\title{
What will it take to adopt smart glasses: A consumer choice based review?
}

\author{
Nuri Basoglu a , Ali Emre Ok a, Tugrul U. Daim ${ }^{\text {b, * }}$ \\ a Izmir Institute of Technology, Izmir, Turkey \\ b Portland State University, Portland, OR 97297, USA
}

\section{A R T I C L E I N F O}

\section{Article history:}

Received 23 November 2016

Accepted 20 April 2017

Available online 26 April 2017

\begin{abstract}
A B S T R A C T
Wearable technologies have become a reality already. Their impact in some fields has already been seen. We explore the factors which are important and help the adoption of these technologies. Specifically we study the adoption factors of smart glasses. Technology adoption process depends on preferences and needs of people who use the systems under study. We explore these phenomenon through two frameworks: Product Characteristics and User Intention Characteristics. The purpose of the first framework is to examine the effects of smart glass design features; Stand-alone device, field of view, interaction, price, and display resolution on user preference through an experimental study and we use conjoint analysis. The second framework explore many more factors such as self-efficacy, anxiety, involvement, risk-task characteristics, enjoyment, usefulness, ease of use, attitude and intention. A web survey supplemented by visual aids was used.
\end{abstract}

(๑) 2017 Elsevier Ltd. All rights reserved.

\section{Introduction}

Information technology (IT) applies computer and telecommunication technologies in order to process data effectively. Smart devices enabled by information technology (IT) have become the essential parts of our daily life. As the devices got smaller and integrated into other devices, the standards of life have improved. The latest phase in the spectrum of these smart devices feature wearable technologies [10]. While many of these devices are currently used for fitness and health, many other applications seem possible in the near future. Smart glasses have also enabled many new applications. These wearable technologies advanced the concept of glasses to the point that the glasses keep adjusting to your changing vision [38]. They certainly surpassed the initial google glass concept and become much smarter [39]. This study explores product characteristics through design factors of smart glasses and examine the user intention characteristics through factors impaction user' potential decision on the use of smart glasses.

As today's technology companies and scientists in labs or universities invent and innovate ways to use smart technology in order

\footnotetext{
* Corresponding author.

E-mail address: TUGRUL.U.DAIM@PDX.EDU (T.U. Daim).
}

to enhance our daily life, smart technology finds new applications in the medical, education, entertainment, sports and commerce sectors. It enables these sectors to develop higher quality, easy to use products and services. For example smart cars consume less fuel and have less carbon emissions. Smart phones enhance life and bring people together. Today smart glasses have already demonstrated potential to take a significant role in enhancing product and services providing users easy and useful innovations.

We focused on smart glasses in this study and explored different perspectives playing a role in consumers' adoption.

\section{Literature review}

Prior research on human-computer interaction $(\mathrm{HCI})[1]$ indicated that the existing interfaces may be a bottleneck for the effective utilization of the available information flow with the development of computing, communication and display technologies [43]. Fischer [23] indicated that the challenge is to find out how to improve the way people use computers to work, think, communicate, learn, critique, explain, argue, debate, observe, decide, calculate, simulate, and design. HCI Scientists have studied how human factors, ergonomics, cognitive psychology, behavioral psychology and psychometrics, systems engineering, and computer science interact [26]. One of the important factors which has been studied is Usability. It is defined as the extent to which the user and 
the interface can communicate clearly, without misunderstanding through the interface [13] or "the capability in human functional terms to be used easily and effectively by the specified range of users, given specified training and user support, to fulfill the specified range of tasks within the specified range of environmental scenarios" [49].

Wearable technologies have entered our lives fast and have been a focus of recent research. Prior research explored the use of wearable technology in many different sectors. Sultan [50] explores new and potentially disruptive uses of wearable technology in health care and medical education. Griggs [24]], Larson et al. [33] and Ahmed et al. [2] also studied the use of wearable technologies in the health care sector. Bower and Sturman [12] explored these technologies in the education sector.

Smart glasses have been the focus of recent research [37]. Wu et al. [53] studied the impact of use of smart glasses service evaluations and differences between the genders. Hao and Helo [25] studied wearable technologies and explored how they support cloud manufacturing. Their focus was also smart glasses and their impact on user experience in making them more productive (see Fig. 1).

Several studies have explored technology adoption. Many have been based in the seminal work by Davis [20], who studied technology acceptance and proposed the technology acceptance model (TAM) which suggests user's motivation of technology can be influenced by perceived ease of use and perceived usefulness. His hypothesis was that the attitude of user is a main determinant to decide using of technology. Davis described perceived usefulness as "the degree to which a person believes that using a particular system would enhance his/her job performance" and perceived ease of use as "the degree to which a person believes that using a particular system would be free of effort”.

Basoglu et al. [3-5], Daim et al. [19]; Behkami and Daim [9] and Topacan et al. [52] explored technology adoption in the health sector. Basoglu et al. [6,8], Daim et al. [18] and Tanoglu et al. [51] studied adoption of software in business settings. Seneler et al. $[47,48]$ explored the adoption of online services. Basoglu et al. [7], Daim et al. [17], Kargin et al. [30] and Phan et al. [44] explored adoption of mobile services. We reviewed factors explored in these studies and developed a limited taxonomy for this exploratory research:
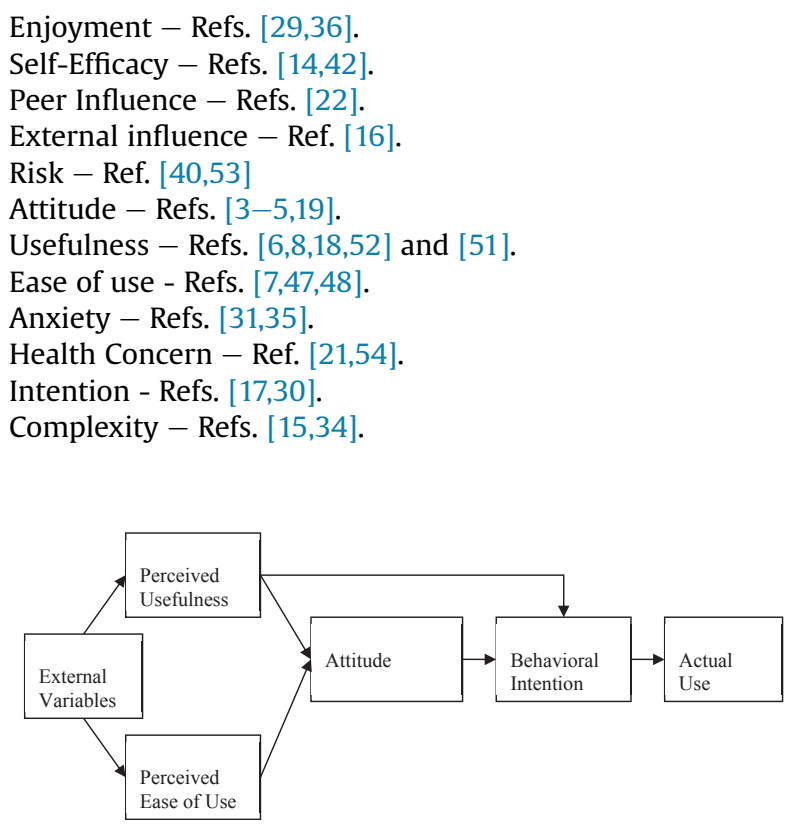

Fig. 1. Technology Acceptance Model [20].
The next section will explain the methods used to explore these factors.

\section{Methodology}

Factors identified through the literature review have been identified through two frameworks.

First framework evaluated alternative designs. Conjoint analysis [27] was used for this framework. Conjoint analysis is used in marketing research to examine customer preferences and the users' potential decisions on the use of products or services. Conjoint analysis helps researchers to determine the relative importance of each attribute of a product or a service and identify market segments for which distinct products can be chosen such as the case of a business traveler and a student traveler with different preferences [28]. This framework helped us to evaluate what we refer to as product characteristics.

The second framework explored user intention characteristics identified through the literature review.

A survey was administered to collect data to accomplish the objectives for both frameworks. There were 81 responses for conjoint analysis and 122 for the user intention characteristics analysis.

First part introduced the purpose of the experimental study. The second part introduced the smart glasses through videos related to smart glasses. The third part contained demographic questions to gather data about age, gender and education. The fourth part included user intention characteristics questions about smart glasses addressing our first framework of study. These characteristics included self-efficacy, anxiety, involvement, risk-task characteristics, enjoyment, usefulness, ease of use, attitude and intention for user smart glasses interaction. This part asked for agreement and disagreement with various statements on a fourpoint likert scale ranging from (1) disagree to (4) agree.

The final page includes conjoint analysis part of the experimental study. The fifth and the final part contained the main conjoint analysis question which helped us with the product characteristics addressing the second framework of study. In this part there were informative pictures and instructions for clarity.

Traditional full-profile conjoint analysis as used for this study. Various product descriptions are developed and presented to the participants for preference evaluations. Attributes and levels of the product were specified in order to measure utility. Attribute is the feature of the product and level is the values of each attributes. Alternative is the set of attributes and its levels. All attributes that characterize the alternatives were considered. If some alternatives were not feasible to subjects, these profiles were removed. Participants ranked alternatives according to their agreements or disagreements. Table 1 presents the alternatives generated for the conjoint analysis.

As presented we limited the attributes to five:

1. Standalone device has two levels: "Yes" and "No".

2. Field of view has two levels: " $12^{\circ}$ " and " $65^{\circ}$ "

3. Interaction has two levels: "Voice recognition\& Touchpad" and "Hand gestures"

4. Price has three levels; “300\$”, “600\$” and "1000\$”.

5. Display Resolution has two levels " $1024 \times 768$ " and " $640 \times 360$ "

A total of eight alternatives were generated. For instance Alternative 4 represents non standalone device, $65^{\circ}$ field of view, interaction with voice recognition\& touchpad, $600 \$$ price and $1024 \times 768$ pixel display resolution. Participants ranked these alternatives with respect to their assessments about smart glasses from the most (1) to the least (8) desirable. 
Table 1

SPSS conjoint alternatives.

\begin{tabular}{|c|c|c|c|c|c|}
\hline Alternative & Standalone device & Field of view & Interaction & Price & Display Resolution \\
\hline 1 & No & $12^{\circ}$ & Voice recognition \& Touchpad & $300 \$$ & $1024 \times 768$ \\
\hline 2 & Yes & $65^{\circ}$ & Voice recognition \& Touchpad & $600 \$$ & $640 \times 360$ \\
\hline 3 & Yes & $12^{\circ}$ & Hand gestures & $600 \$$ & $1024 \times 768$ \\
\hline 4 & No & $65^{\circ}$ & Voice recognition \& Touchpad & $600 \$$ & $1024 \times 768$ \\
\hline 5 & No & $65^{\circ}$ & Hand gestures & $600 \$$ & $1024 \times 768$ \\
\hline 6 & Yes & $12^{\circ}$ & Voice recognition \& Touchpad & $600 \$$ & $1024 \times 768$ \\
\hline 7 & Yes & $65^{\circ}$ & Hand gestures & $1000 \$$ & $1024 \times 768$ \\
\hline 8 & No & $12^{\circ}$ & Hand gestures & $300 \$$ & $640 \times 360$ \\
\hline
\end{tabular}

Table 2

The profile of the participants.

\begin{tabular}{lll}
\hline Variable & Percentage & Frequency \\
\hline Gender & & \\
Male & $49.2 \%$ & 63 \\
Female & $50.8 \%$ & 59 \\
Age & & \\
24 and lower & $25.8 \%$ & 32 \\
$25-29$ & $60.9 \%$ & 73 \\
$30-34$ & $7.8 \%$ & 10 \\
$35-39$ & $2.3 \%$ & 3 \\
$40-44$ & $1.6 \%$ & 2 \\
45 and higher & $1.6 \%$ & 2 \\
Education & & 2 \\
High school graduate & $1.6 \%$ & 24 \\
University student & $19.7 \%$ & 96 \\
University graduate & $78.7 \%$ & \\
\hline
\end{tabular}

Standalone smart glass models [45] have their own mobile operating system such as Android. They have also include a processor, RAM and internal storage. Other smart glasses which do not have own hardware and software connect to other devices like mobile phones through universal series bus (USB) interface. These phones leverage operating system of mobile phones or tablets. Thus standalone phones have advantage over non-standalone phones for being an independent device while non-standalone phones are less expensive and light in weight.

Various smart glasses which are ready to be launched or those launched already have different field of view (FOV) features [32]. FOV represents to the angle of viewers' perspective of display. Humans have capability of $180^{\circ}$ horizontal field of view. Large field of view increases the satisfaction level of viewers. Companies work to enhance field of view feature to gain competitive advantage. FOV for smart glasses varies between $12^{\circ}$ and $65^{\circ}$.

Interaction deals with the commands of the smart glasses. Bertarini [11] groups interaction approaches into two: free form and others. Free form interaction includes eye tracking, wink detection, voice commands, and detection of gestures by fingers or hands. Free form devices don't require and additional device to perform or control but some are controlled by pointers. Gesturebased interaction smart glasses may be more ideal than others which require external pointers, keyboard or smart phones. Voice recognition based devices were already launched for mobile devices. It may also be useful for smart glasses. Touchpad technology is generally preferred it requires less time than integrating gesture technologies.

Price is an important factor for potential user. In the case of smart glasses companies innovate to decrease production costs to increase their share of the market [32].

Resolution is measured with the number of pixels the display has and how these pixels are packed. The higher resolution has better display quality and more satisfactory for the viewer. Display resolution of smart glasses varies between $320 \times 240$ and $1920 \times 1080(\mathrm{HD})$ [32].

The next section will present the results of analyses for both frameworks: product characteristics (conjoint analysis) and user intention characteristics.

\section{Results and discussion}

The results of the study are presented in this section.

\subsection{The profile of the participants}

The profile of the participants who joined survey study can be seen in Table 2.

The results show that the sample mostly aged between twentyfive and twenty-nine. 59 participants are female and 63 participants are male.

\subsection{Product characteristics}

The relative importance of each attribute and levels of each preferred attribute are explored through the conjoint analysis. The output of conjoint analysis, which shows the importance of attributes and its associated levels, is shown below (Table 3 ).

Table 3

Product utility table.

\begin{tabular}{|c|c|c|c|}
\hline & & Utility Estimate & Std. Error \\
\hline \multirow[t]{2}{*}{ Standalone device } & Yes & 1.735 & 0.349 \\
\hline & No & -1.735 & 0.349 \\
\hline \multirow[t]{2}{*}{ Interaction } & Hand gesture & 0.227 & 0.145 \\
\hline & Voice rec. \& Touchpad & -0.227 & 0.145 \\
\hline \multirow[t]{3}{*}{ Price } & $300 \$$ & 2.000 & 0.888 \\
\hline & $600 \$$ & -0.035 & 0.168 \\
\hline & $1000 \$$ & -1.965 & 0.839 \\
\hline \multirow[t]{2}{*}{ Display resolution } & $640 \times 360$ & -0.919 & 0.252 \\
\hline & $1024 \times 768$ & 0.919 & 0.252 \\
\hline \multirow[t]{2}{*}{ Field of view } & 12 & -1.346 & 0.349 \\
\hline & 65 & 1.346 & 0.349 \\
\hline (Constant) & & 3808 & 0.237 \\
\hline
\end{tabular}


Table 4

Average importance values.

\begin{tabular}{ll}
\hline Importance Values & \\
\hline Standalone device & $28 \%$ \\
Interaction & $4 \%$ \\
Price & $32 \%$ \\
Display resolution & $15 \%$ \\
Field of view & $22 \%$ \\
\hline
\end{tabular}

According to conjoint analysis results which are shown in utility table, $300 \$$ smart glass price has highest utility value which is 2.000. Therefore price attribute with $300 \$$ level is the most important and desired value among the other values. The second important value is standalone device attribute which is 1735 . The third highest utility value is field of view with $65^{\circ}$. High display resolution and hand gesture interaction followed these values. Besides $1000 \$$ smart glass price has the least desirable value which is -1.965 . Non standalone devices, field of view with $12^{\circ}$ and low display resolutions have dissatisfactory values as shown in Table 3.

Table 4 shows the average importance values that influence the user preference. The most important factor which influences a participant's preference is price with $32 \%$. The second is standalone device (28\%) which is close to the price. Field of view is the third important factor with $22 \%$. Display resolution scored $15 \%$ and interaction received the lowest value (4\%).

Conjoint analysis results show that the participants desire to use low priced smart glasses. Price is the determinant factor for potential users. This study shows that low price has positive influence on design factor of smart glasses. Standalone device is the second important and desired smart glass attribute according to the participants. In that context standalone variable has positive influence on participants because of not dealing with another device. Potential smart glass users also intend to use smart glasses with large field of view. This increases the satisfaction level of participants and it has a positive influence on participants' decision. It is surprising that interaction has the lowest level of importance. Moreover hand gesture is more desired interaction than voice recognition \& touchpad. The least desirable smart glass attribute is high price product which has a negative influence on participants.

Part-worth utilities (PWU) of alternative smart glasses which helps to determine which product design characteristics are the most or least desirable and at what levels are shown in Table 5.

Table 5 shows that participants mostly desired to use alternative number 2 which is a standalone device with a large field of view, voice recognition\& touchpad interaction, medium price and $640 \times 360$ display resolution. Participants disliked 8th alternative which is a non-standalone device with a small field of view, hand gesture interaction, low price and $640 \times 360$ display resolution. Non standalone device, small field of view and medium display resolution all have negative influence.

\subsection{User intention characteristics}

Survey data related with user intention characteristics such as self-efficacy, anxiety, involvement, risk-task characteristics, enjoyment, usefulness, ease of use, attitude and intention were collected in order to analyze their potential effects on the design of smart glasses. Participants ranged each of characteristics according to their agreement and disagreement degrees with various statements on a four-point likert scale ranging from (1) disagree to (4) agree. The results are shown in Table 6.

In this study the mean value of enjoyment received the highest score with 3.3. Participants also prefer to have self-efficacy to use smart glasses. They are primarily influenced by their friends, family and neighborhood in their opinions to use one of the smart glasses (peer influence). The participants are also influenced by news, advertisements and other external things (external influence). They partially agree that using smart glass is a risky task (risk). Their attitude towards using smart glass is positive (attitude). Participants agree that they are easy to use and useful (ease of use and usefulness). They have a little bit anxiety and health concern while using smart glasses (anxiety and health concern). It is also seen that they are not exactly ready using smart glasses (intention). Finally

Table 5

Product ranks.

\begin{tabular}{|c|c|c|c|c|c|c|}
\hline Rank & Alternative & Standalone device & Field of view & Interaction & Price & Display Resolution \\
\hline 1 & 2 & Yes & $65^{\circ}$ & Voice recognition \& Touchpad & $600 \$$ & $640 \times 360$ \\
\hline 2 & 3 & Yes & $12^{\circ}$ & Hand gestures & $600 \$$ & $1024 \times 768$ \\
\hline 3 & 7 & Yes & $65^{\circ}$ & Hand gestures & $1000 \$$ & $1024 \times 768$ \\
\hline 4 & 4 & No & $65^{\circ}$ & Voice recognition \& Touchpad & $600 \$$ & $1024 \times 768$ \\
\hline 5 & 5 & No & $65^{\circ}$ & Hand gestures & $600 \$$ & $1024 \times 768$ \\
\hline 6 & 1 & No & $12^{\circ}$ & Voice recognition \& Touchpad & $300 \$$ & $1024 \times 768$ \\
\hline 7 & 6 & Yes & $12^{\circ}$ & Voice recognition \& Touchpad & $600 \$$ & $1024 \times 768$ \\
\hline 8 & 8 & No & $12^{\circ}$ & Hand gestures & $300 \$$ & $640 \times 360$ \\
\hline
\end{tabular}

Table 6

Statistics for user intention characteristics.

\begin{tabular}{|c|c|c|c|c|c|c|c|}
\hline & Mean & Standard deviation & Median & Mode & Min & Max & $\mathrm{N}$ \\
\hline Enjoyment & 3.311 & 0.796 & 3 & 4 & 1 & 4 & 122 \\
\hline Self-Efficacy & 3.131 & 0.782 & 3 & 3 & 1 & 4 & 122 \\
\hline Peer Influence & 3.008 & 0.766 & 3 & 3 & 1 & 4 & 122 \\
\hline External influence & 2.922 & 0.713 & 3 & 3 & 1 & 4 & 122 \\
\hline Risk & 2.677 & 0.968 & 3 & 3 & 1 & 4 & 122 \\
\hline Attitude & 2.644 & 0.424 & 2.7 & 2.7 & 1 & 4 & 122 \\
\hline Usefulness & 2.628 & 0.722 & 2.7 & 2.7 & 1 & 4 & 122 \\
\hline Ease of use & 2.426 & 0.362 & 2.5 & 2.5 & 1 & 4 & 122 \\
\hline Anxiety & 2.098 & 0.797 & 2 & 2 & 1 & 4 & 122 \\
\hline Health Concern & 2.032 & 0.953 & 2 & 2 & 1 & 4 & 122 \\
\hline Intention & 1.901 & 0.837 & 2 & 2 & 1 & 4 & 122 \\
\hline Complexity & 1.803 & 0.664 & 2 & 2 & 1 & 4 & 122 \\
\hline
\end{tabular}




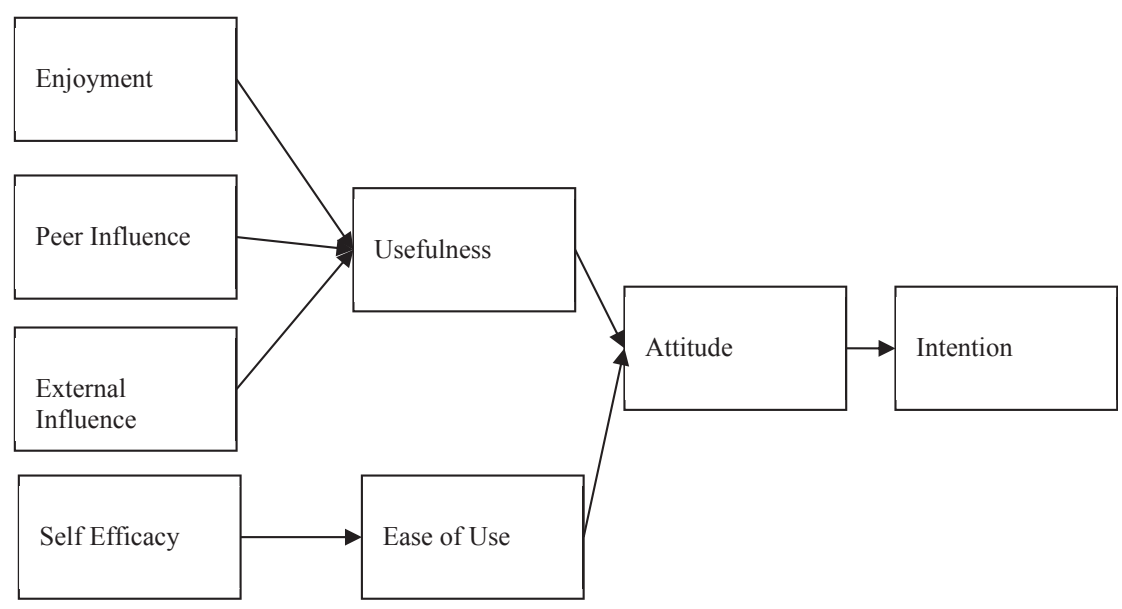

Fig. 2. Propositions for further research.

participants found using smart glasses is not a complex task (complexity).

\section{Conclusions}

While limited, the study identified interesting perceptions of potential customers of smart glasses. As reported by Lamkin and Charara [32] attributes and technologies embedded into smart glasses advance at an increasing pace. However they have not become a common household item as the smart phones or tablets have. One of the important factors identified in this study is the cost of the smart glasses. While that is not surprising, it is encouraging that the smart glasses may be getting ready to be adopted by masses as the prices go down. So a future study may explore the following propositions:

\section{P1: Price influences the adoption of smartglasses}

The results also indicated that the users do not want to deal with the complexities of synching multiple devices such as their smart phones and smart glasses to be able to use their smart glasses. For this reason the users seem to prefer standalone devices. However this perception might change if the same people bought and used these devices. First of all the standalone devices would be more expensive due to higher materials and manufacturing costs. Second, the hardware or software on these devices may get obsolete as those on smartphones have much longer life due to frequent software updates. Therefore two related propositions may need to be explored further:
P2: Smart glass users prefer standalone devices

P3: Smart glass users avoid complexity

These three propositions were based on the conjoint analysis results which explored product characteristics.

The analysis on user intention characteristics revealed some insight as well. Other results while limited indicate more preference of enjoyment and influence by others. This indicates that users may still be seeing smart phones as expensive toys and to a degree an item of status. This may also be due to the fact that this study was conducted in Turkey. This may lead to another set of propositions:

P4: Smart glass users prefer enjoyment

P5: Smart glass users seek self efficacy

P6: Smart glass users are influenced by others.

These propositions can be developed further into a model as shown below (see Fig. 2).

Our analysis of this model through the data collected is presented in Table 7. The linkages found to have significance are listed below (see Fig. 3).

The above figure reflects the resulting model with statistically significant linkages. Above model could be hypothesized for a second round of a survey study to verify the theoretical contributions.

This study was a preliminary analysis of perceptions. Smart glasses are being explored for many advanced uses in many different sectors today. Medical applications ranging from education, clinical applications to health care seem to be attracting a lot of

Table 7

Regression analyses results.

\begin{tabular}{|c|c|c|c|c|c|}
\hline & \multirow{2}{*}{$\frac{\text { Unstandardized Coefficients }}{\text { B }}$} & \multicolumn{2}{|c|}{ Standardized Coefficients } & \multirow[t]{2}{*}{$\mathrm{t}$} & \multirow[t]{2}{*}{ Sig. } \\
\hline & & Std. Error & Beta & & \\
\hline (Constant) & 0.355 & 0.247 & & 1.436 & 0.154 \\
\hline Enjoyment & 0.317 & 0.071 & 0.350 & 4.460 & 0.000 \\
\hline External influence & 0.419 & 0.079 & 0.413 & 5.270 & 0.000 \\
\hline \multicolumn{6}{|c|}{ a. Dependent Variable: Usefulness $\mathrm{R}^{2}=0.43$} \\
\hline (Constant) & 1.752 & 0.119 & & 14.732 & 0.000 \\
\hline Usefulness & 0.340 & 0.044 & 0.579 & 7.784 & 0.000 \\
\hline \multicolumn{6}{|c|}{ a. Dependent Variable: Attitude $\mathrm{R}^{2}=0.34$} \\
\hline (Constant) & -0.421 & 0.433 & & -0.972 & 0.333 \\
\hline Attitude & 0.878 & 0.162 & 0.444 & 5.433 & 0.000 \\
\hline \multicolumn{6}{|c|}{ a. Dependent Variable: Intention $\mathrm{R}^{2}=0.20$} \\
\hline
\end{tabular}




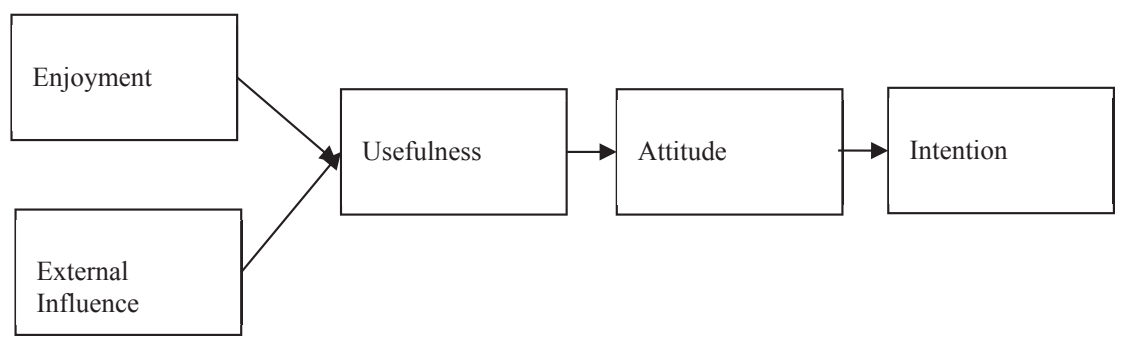

Fig. 3. Modified Propositions for further research.

attention $[24,33,50]$ and [2]. So further studies exploring the relationship of design attributes to actual results would help optimize smart glass designs.

This study contributes to the research on adoption of wearable technologies leveraging research on adoption of information technologies in general.

\section{Acknowledgements}

A prior version of this paper was presented at PICMET 2015 conference in Portland, OR USA [ [41].

\section{References}

[1] ACM, Specialist Interest Group on Computer Human Interaction Curriculum Development Group, Technical report, ACM, ACM New York, 1992.

[2] F. Ahmed, D. Yilmaz, S. Ahmed, M.A. Thaha, Can wearable technology be used to deliver sustainable global surgical interventions? Int. J. Surg. 36 (1) (November 2016) S100.

[3] N. Basoglu, et al., New product development for the healthcare industry: a case study of diet software, Health Policy Technol. 1 (2) (2012a) 93-104.

[4] N. Basoglu, T. Daim, U. Topacan, Determining patient preferences in remote monitoring, J. Med. Syst. 36 (3) (2012b) 1389-1401.

[5] N. Basoglu, T. Daim, H.C. Atesok, M. Pamuk, Exploring the impact of information technology on health information seeking behaviour, Int. J. Bus. Inf Syst. 5 (No 3) (2010) 291-308.

[6] N. Basoglu, T. Daim, O. Kerimoglu, Organizational adoption of enterprise resource planning systems: a conceptual framework, J. High Technol. Manag. Res. 18 (1) (2007) 73-97.

[7] N. Basoglu, T. Daim, E. Polat, Exploring adaptivity in service development: case of mobile platforms, J. Prod. Innov. Manag. 31 (3) (May 2014) 501-515.

[8] N. Basoglu, T. Daim, E. Sofuoglu, A decision methodology for customizing software products, Int. J. Ind. Syst. Eng. 4 (No 5) (2009) 554-576.

[9] N. Behkami, T. Daim, Health information technology adoption, Health Policy Technol. 5 (No 2) (2016) 166-188.

[10] Bell L, The Best Wearable Tech And Fitness Gadgets Of 2017, Forbes, April 3 2017, available at: https://www.forbes.com/sites/leebelltech/2017/04/03/thebest-wearable-tech-and-health-and-fitness-gadgets-of-2017/ \#66aae6791498.

[11] M. Bertarini, Smart Glasses: Interaction, Privacy and Social Implications Ubiquitous Computing Seminar FS2014 Student Report, 2014.

[12] M. Bower, D. Sturman, What are the educational affordances of wearable technologies? Comput. Educ. 88 (October 2015) 343-353.

[13] P.Y.K. Chau, J.H. Hu, Investigating healthcare professionals' decisions to accept telemedicine technology: an empirical test of competing theories, Inf. Manag. 39 (2002) 277-287.

[14] K. Chen, A.H.S. Chan, Predictors of gerontechnology acceptance by older Hong Kong Chinese, Technovation 34 (2) (February 2014) 126-135.

[15] J. Chin, S. Lin, Investigating users' perspectives in building energy management system with an extension of technology acceptance model: a case study in indonesian manufacturing companies, Proc. Comput. Sci. 72 (2015) 31-39.

[16] S. Chung, K.Y. Lee, K. Kim, Job performance through mobile enterprise systems: the role of organizational agility, location independence, and task characteristics, Inf. Manag. 51 (6) (September 2014) 605-617.

[17] T. Daim, N. Basoglu, B. Kargin, K. Phan, Service innovation adoption: case of value added mobile services, J. Knowl. Econ. 5 (4) (2014) 784-802.

[18] T. Daim, N. Basoglu, I. Tanoglu, A critical assessment of information technology adoption: technical, organizational and personal perspectives, Int. J. Bus. Inf. Syst. 6 (3) (2010) 315-335.

[19] T. Daim, N. Basoglu, U. Topacan, Adoption of health information technologies: case of wireless monitor for diabetes and obesity patients, Technol. Anal. Strateg. Manag. 25 (8) (2013) 923-938.

[20] F.D. Davis, Perceived usefulness, perceived ease of use, and user acceptance of information technologies, MIS Q. 13 (1989) 319-340.
[21] A.J. Ducey, M.D. Coovert, Predicting tablet computer use: an extended Technology Acceptance Model for physicians, Health Policy Technol. 5 (3) (September 2016) 268-284.

[22] V. Dutot, Factors influencing Near Field Communication (NFC) adoption: an extended TAM approach, J. High Technol. Manag. Res. 26 (1) (2015) 45-57.

[23] G. Fischer, User modeling in human-computer interaction, User Model. UserAdapt. Interact. 11 (2001) 65-86.

[24] J. Griggs, Wearable technology could revolutionise how we monitor health, New Sci. 225 (3013) (21 March 2015) 24-25.

[25] Y. Hao, P. Helo, The role of wearable devices in meeting the needs of cloud manufacturing: a case study, Robot. Comput. Integr. Manuf. 45 (June 2017) $168-179$.

[26] H.R. Hartson, Human-computer interaction: interdisciplinary roots and trends, J. Syst. Softw. 43 (1998) 103-118.

[27] A. Hermelbracht, B. Koeper, Development of new library services by means of Conjoint Analysis, Libr. Hi Tech. 24 (2006) 595-603.

[28] IBM_Corporation, IBM SPSS Conjoint 20 Manual, 2011.

[29] J. Ingham, J. Cadieux, A.M. Berrada, e-Shopping acceptance: a qualitative and meta-analytic review, Inf. Manag. 52 (1) (January 2015) 44-60.

[30] B. Kargin, N. Basoglu, T. Daim, Factors affecting the adoption of mobile services, Int. J. Serv. Sci. 1 (2) (2009) 29-52.

[31] T. Kummer, J. Recker, M. Bick, Technology-induced anxiety: manifestations, cultural influences, and its effect on the adoption of sensor-based technology in German and Australian hospitals, Inf. Manag. 54 (1) (January 2017) 73-89.

[32] P. Lamkin, S. Charara, The best smartglasses 2017: snap, Vuzix, ODG, Sony \& more, Wearable, available at: https://www.wareable.com/headgear/the-bestsmartglasses-google-glass-and-the-rest, Jan 13, 2017.

[33] B.J. Larson, D. Mejia, T. Marquez, P. Reinhard, Using wearable technology to optimize maternal positioning and facilitate progression of labor, J. Obstet. Gynecol. Neonatal Nurs. 45 (3) (June 2016) S23.

[34] A. Lazard, M. Mackert, User evaluations of design complexity: the impact of visual perceptions for effective online health communication, Int. J. Med. Inf. 83 (10) (October 2014) 726-735.

[35] L. Lazuras, A. Dokou, Mental health professionals' acceptance of online counseling, Technol. Soc. 44 (February 2016) 10-14.

[36] R. Li, T. Chung, A. Fiore, Factors affecting current users' attitude towards eauctions in China: an extended TAM study, J. Retail. Consum. Serv. 34 (January 2017) 19-29.

[37] Linoski A, Wearable Technology, Smart Watches to Google Glass for Librarians, Tom Bruno (Ed.). Rowman \& Littlefield, Lanham, MD (2015), The Journal of Academic Librarianship, vol. 42, 3, May 2016, 287.

[38] Matchar E, These "Smart Glasses" Adjust To Your Vision Automatically, SMITHSONIAN.COM, February 9, 2017, available at http://www. smithsonianmag.com/innovation/these-smart-glasses-adjust-your-visionautomatically-180962078/.

[39] R. Metz, Google glass is dead; long live smart glasses, MIT Technol. Rev. 118 (1) (Jan Feb 2015) 79-82 available at: https://www.technologyreview.com/s/ 532691/google-glass-is-dead-long-live-smart-glasses/.

[40] T. Natarajan, S.A. Balasubramanian, D.L. Kasilingam, Understanding the intention to use mobile shopping applications and its influence on price sensitivity, J. Retail. Consum. Serv. 37 (July 2017) 8-22.

[41] Ok A, Basoglu N, Daim T, Exploring the Design Factors of Smart Glasses, Management of the Technology Age, Portland International Conference on Management of Engineering and Technology Proceedings, 2015.

[42] A.B. Ozturk, A. Bilgihan, K. Nusair, F. Okumus, What keeps the mobile hotel booking users loyal? Investigating the roles of self-efficacy, compatibility, perceived ease of use, and perceived convenience, Int. J. Inf. Manag. 36 (6, Part B) (December 2016) 1350-1359.

[43] V.I. Pavlovic, R. Sharma, T.S. Huang, Visual Interpretation of Hand Gestures for Human-computer Interaction, 1997.

[44] K. Phan, T. Daim, N. Basoglu, B. Kargin, Exploring technology acceptance across countries: case of mobile services adoption in the USA and Turkey, Int. J. Serv. Sci. 3 (2/3) (2010) 216-231.

[45] G. Roberts, Is google glass a stand alone mobile device or is it a smart phone accessory?, available at: https://www.quora.com/Is-Google-Glass-a-standalone-mobile-device-or-is-it-a-smart-phone-accessory, Mar 23, 2013.

[47] C. Seneler, N. Basoglu, T. Daim, Interface feature prioritization for web services: case of online flight reservations, Comput. Hum. Behav. 25 (2009) 
$862-877$.

[48] C. Seneler Ozen, N. Basoglu, T. Daim, An empirical analysis of the antecedents of adoption of online servcies: a prototype-based framework, J. Entrep. Inf. Manag. 23 (4) (2010) 417-438.

[49] D. Shackel, Usability: context, framework, definition, design and evaluation, in: Human Factors for Informatics Usability, Cambridge University Press, 1991.

[50] N. Sultan, Reflective thoughts on the potential and challenges of wearable technology for healthcare provision and medical education, Int. J. Inf. Manag. 35 (5) (October 2015) 521-526.

[51] I. Tanoglu, N. Basoglu, T. Daim, Exploring technology diffusion: case of information technologies, Int. J. Inf. Technol. Decis. Mak. 9 (2) (2010) 195-222.
[52] U. Topacan, N. Basoglu, T.U. Daim, Exploring the adoption of technology driven services in the healthcare industry, Int. J. Inf. Syst. Serv. Sect. 2 (No 1) (2010) 71-93.

[53] L. Wu, A. Fan, A.S. Mattila, Wearable technology in service delivery processes: the gender-moderated technology objectification effect, Int. J. Hosp. Manag. 51 (October 2015) 1-7.

[54] C.W. Yoo, S. Parameswaran, R. Kishore, Knowing about your food from the farm to the table: using information systems that reduce information asymmetry and health risks in retail contexts, Inf. Manag. 52 (6) (September 2015) 692-709. 